\title{
A Comparison of Regeneration Dynamics Following Gap Creation in a Degraded Grassland
}

\author{
KAN Haiming ${ }^{1, ~ a, ~ S U N ~ T i e j u n ~}{ }^{1, b}$, WU Juying ${ }^{1, ~ c}$, PANG Zhuo ${ }^{1, d}$, HU Wei, e \\ ${ }^{1}$ Beijing Research \& Development Center of Grass and Environment,Beijing Academy of Agriculture \\ and Forestry Sciences, Beijing 100097, China; \\ corresponding author: ${ }^{a}$ kanhaiming@hotmail.com, ${ }^{b}$ stj_cau@163.com. \\ cwujuying@263.net, ${ }^{\text {}}$ pangzh-84@163.com, ${ }^{\mathrm{T}}$ huwei102205@163.com
}

\begin{abstract}
Key words: reseeding management, restoration ecology, gap disturbance, gap size
Abstract. Seven treatments were implemented in a degraded steppe in north China to evaluate the effects of gap creation on two native species regeneration. Shoot gaps and root gaps $(10 \mathrm{~cm}, 20 \mathrm{~cm}$ and $40 \mathrm{~cm}$ in diameters), no gaps (control). Shoot gaps were formed by removing vegetation without restricting the re-growth of neighbor roots back into the gap.Root gaps were accomplished by using PVC pipes sunk in the soil of shoot gaps. Seedling growth performance after 90 days of growing were recorded for both species. Seedling emergence and survivorship of both species were greater in gaps than in controls.However, the gap size showed a significantly negative effect onAgropyron cristatum's survivorship.Growth performance of Agropyron cristatumandStipa kryloviidiffer in their response to gap disturbance.Gaptreatments had positive effects on seedling growth(including seedling height, dry weight, and numbers of tillers andleaves) of Stipa krylovii, but had negative effects on seedling growth ofAgropyron cristatum. The two species have significantly different responses to gap disturbance. All results suggest that Stipa kryloviiis a gap-enhanced species, and Agropyron cristatumis not. Gap creation promoted the seedling establishment. Different species differ in their regeneration dynamics when the gap is available.
\end{abstract}

\section{Introduction}

Disturbance is an important factor in maintaining species richness in plant communities[1].It operates on adult plants by providing regeneration niches for recruitmentif it has greater relative impact on dominant species [2-4].Gap creation has been shown by many authors to be a key requirement for diversity maintenance in grassland communities[5] and necessary for successful seedling establishment of many species[6], as many species are limited by microsite [7], seed [8].Gaps providean opportunity for regeneration from seed alreadypresent in the seed bank, existing vegetation, or byintroduction from outside the site.

Agropyron cristatumandStipakryloviihave the same photosynthetic pathway and are resistant to drought. In the eastern parts of typical steppes of Inner Mongolia, Stipa kryloviiis often a sub-dominant species with Leymus chinensis dominant, and Agropyron cristatum is mostly a companion species in a semi-arid grassland community[9, 10]. However, nearly $86 \%$ of these grasslands are facing degradation or have been degraded in recent decades due to excess reclamation and overgrazing. Climate change and human activities have amplified the magnitude of these disturbance events[11].Creating gaps is favorable for re-vegetation of seedling establishment and survival is crucial for re-vegetation of degraded grassland[12]. Gaps providean opportunity for regeneration from seed alreadypresent in the seed bank or existing vegetation or byinvasion from outside the site[13].There were few investigations on their seedling establishment under the gap disturbance in semi-arid grassland conditions. Results from this study may contribute to improved techniques for grassland restoration and reconstruction in northern China.

\section{Materials and methods}

The experiment was carried out in the Grassland Vegetation Restoration and Reconstruction Key Laboratory of China, Ministry ofAgriculture Experiment Station $\left(41^{\circ} 52^{\prime} \mathrm{N}, 115^{\circ} 50^{\prime} \mathrm{E}\right.$, altitude 
$1370 \mathrm{~m})$, Saibei administrative region, Hebei province, China. Annual average rainfall range is $350-450 \mathrm{~mm}$, and is summer dominant, with an average of $70 \%$ falling during the growing season (late spring, summer and autumn). Mean annual temperate of the site is $1.41^{\circ} \mathrm{C}$.The accumulated temperature $\geq 10^{\circ} \mathrm{C}$ is $1513.1^{\circ} \mathrm{C}$. The growing season lasts about 100 days. Soils on the study site were chestnut and a little alkaline, and the topography is flat ( $<1 \%$ slope). The natural dominant vegetation species are Leymus chinensis, Stipa krylovii, Artemisia eriopoda, Artemisia tanacetifolia and Cleistogense squarrosa.The main companion species were Bromus inermis, Agropyron cristatum and Poa annua.All the weather data was monitored with an automatic meteorological station whichis located in the center of the site.

Experiment was conducted in a split-plot design, and in each plot a randomized block design was used. The main plots consist of two different species separately(Agropyron cristatum, Stipa krylovii).The treatments were no gap (control), and shoot and root gaps each with diameters of 10, 20 and $40 \mathrm{~cm}$.Both seeds(Agropyron cristatum, Stipa krylovii) were collected from the natural habitat in experimental area in the autumn of 2010. Before the sowing, the germination rate and thousand-grain weight of each species was determined.

\section{Results and Discussion}

Agropyron cristatum and Stipa krylovii showed a completely different response pattern of their seedling performance to gap disturbance.For Stipa krylovii, all seedling growth variables (height, tillers, leaves and dry weight per seedling) were positively related to gap size (Fig.3.A, B, C, D). Gap type, gap size and their interactions affected seedling growth performance.Seedling growth variables (height, tillers, leaves and dry weight per seedling) were all significant, except for leaves of Agropyron cristatum.However, Agropyron cristatum's growth performance showed a significant negative effect with increasing gap size (Fig.4.E, F, G, H). Seedling height in root gaps or shoot gaps significantly decreased as gap size increased, and the other performance (tillers, leaves and dry weight per seedling) showed the same trend (Fig.1,2).But all seedlings of Agropyron cristatumperformed betterintreatments than in the control.

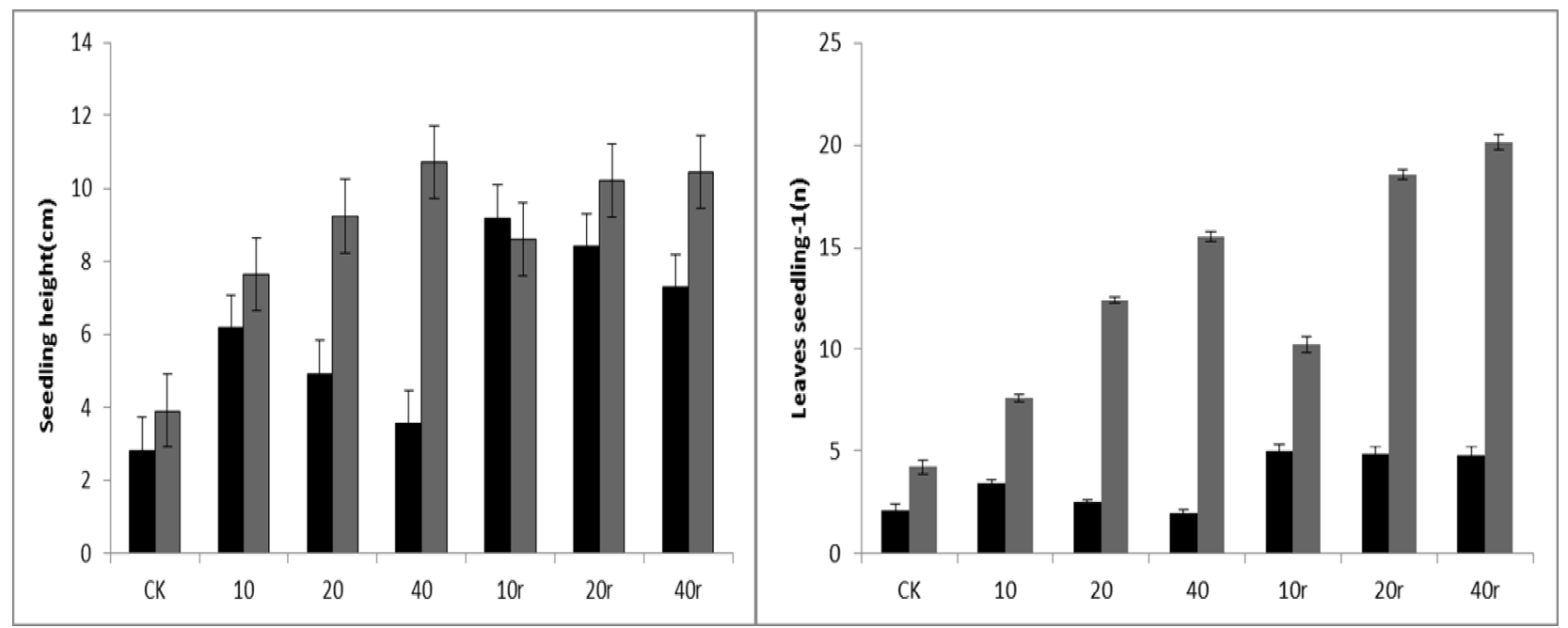

Fig.1. Effects of gap disturbance on seedling performance of Stipa krylovii and Agropyron cristatum ( mean $\pm \mathrm{SE}$, height, number of leaves).

Gap size and root exclusion had significant effects on growth performances of both species. For Stipa krylovii, seedling growth performance was promoted by gap treatment, and all seedlings in root gap had higher growth performance than in shoot gaps, regardless of gap size. Too much work had been done to show the same results. For example, Cahill [14] showed that gaps provided areas of low belowground competitive intensities, this could give a better micro-site for seedlings growth.Armas and Pugnaire [15] and McConnaughay and Bazzaz [16] suggested that the presence of roots in soil might be important in creating physical barriers to seedling root growth. Gap area 
had important effects for plant establishment. However, in my study,Agopyron cristatum showed a significantly negative growth performance in gap treatments. This confirms the studies of Hanley, Fenner [17] and Louda and Rodman [18], which assert that predation may be a key factor that affect the seedling growth. The larger the gap area, the less the above vegetation is, the higher chance of insect feeding, and due to the selectivity of insects feeding [17, 19],Agropyron cristatumcould be more palatableto insectssuch asgrasshoppers or weevils thanStipa krylovii.So the large sized gap disturbance appeared to be more favorable to Stipa krylovii, but small sized gap $(10 \mathrm{~cm})$ disturbance produced the best growth performance of Agropyron cristatum.

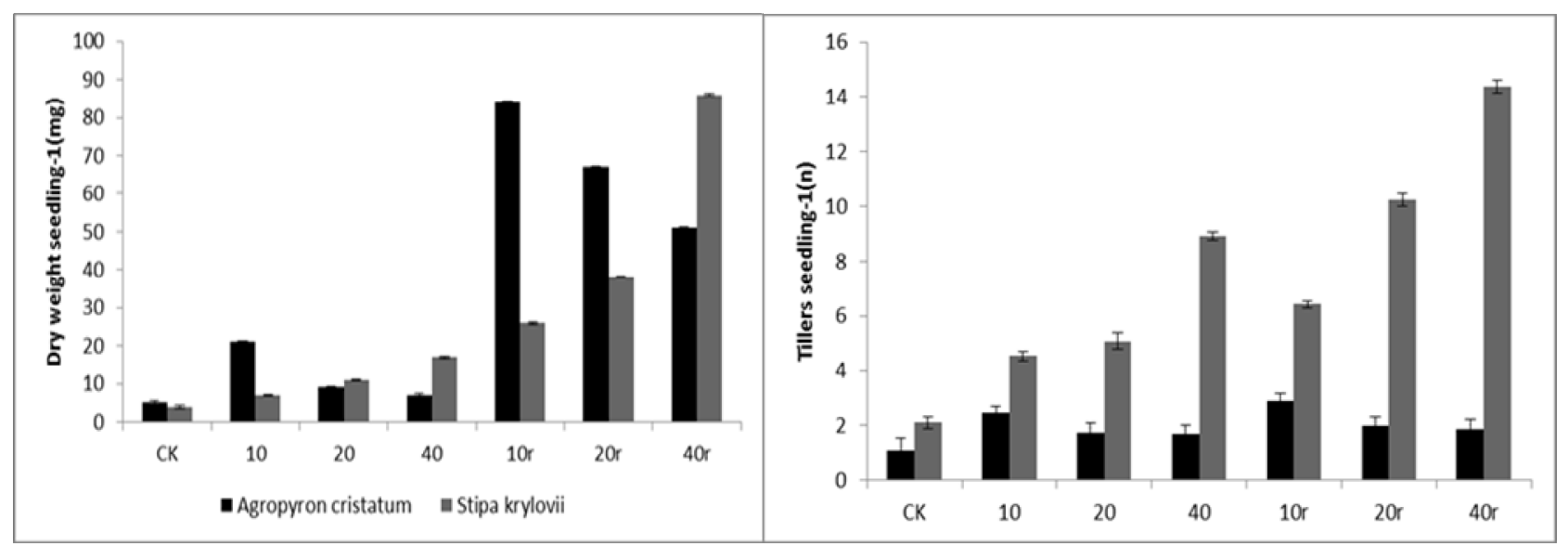

Fig.2. Effects of gap disturbance on seedling performance of Stipa krylovii and Agropyron cristatum ( mean $\pm \mathrm{SE}, \quad$ number of tillers, dry weight per seedling).

The results of this study point to the importance of microsite for establishment of native species in semi-arid grassland.The results showed a trend of decreased seedling survival as gap size increased.
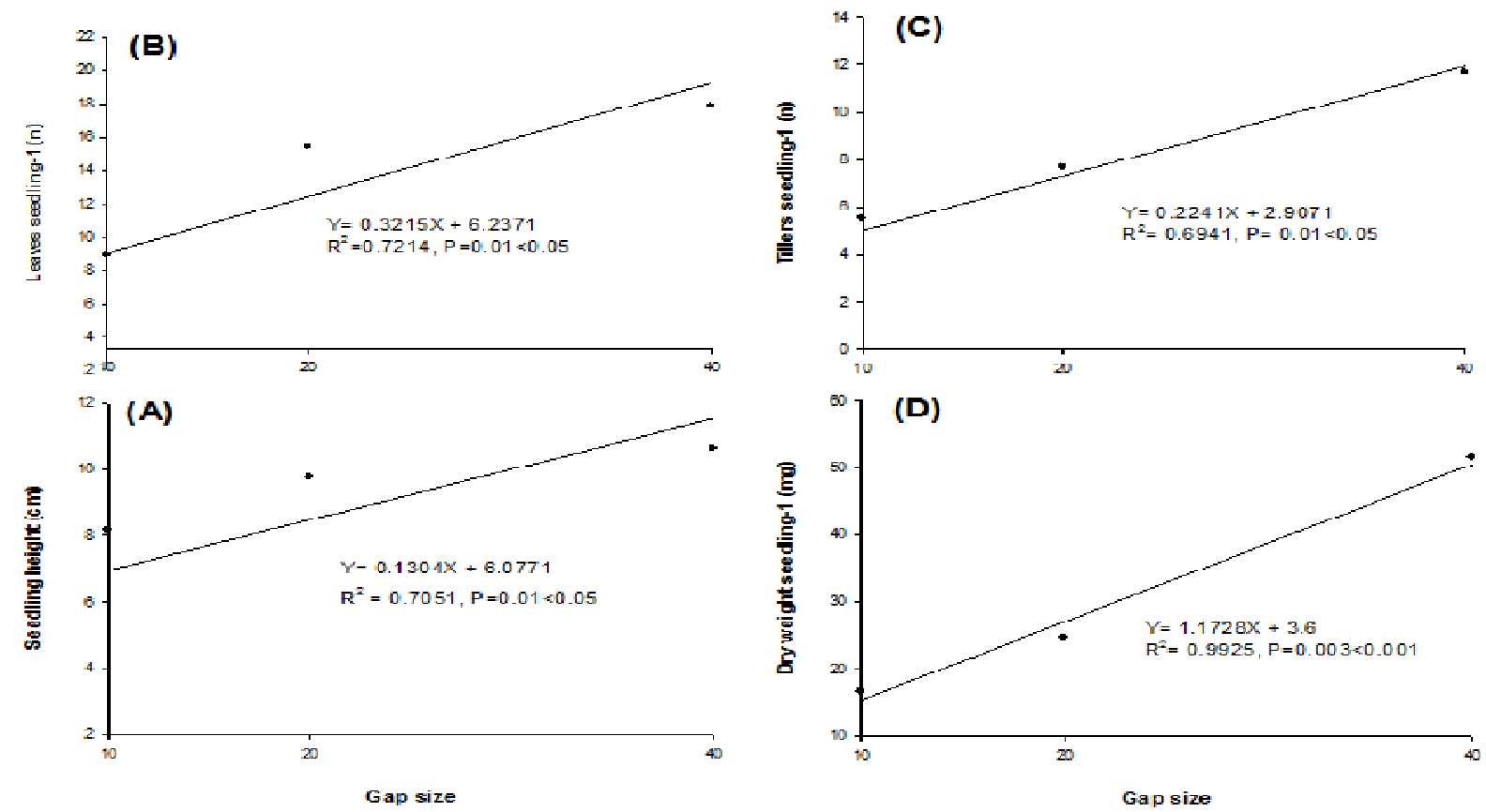

Fig.3.Relationships of gap size and seedling height, number of leaves per seedling, number of tillers per seedling and dry weight per seedling of Stipa krylovii (A, B, C, D)

Gap disturbance significantly increased soil moisture, and slightly increased soil temperature, which could promote the seedling emergence and growth performance of both species compared to controls. Stipa krylovii appeared as a gap enhanced species. Gap size and root exclusion had significantly positive effects on seedling establishment. However, the performance of Agropyron 
cristatum was opposite that of Stipa krylovii, it suffered the limitation of new habitat, and its tolerance to predation was worse than that of Stipa krylovii. It's more palatable to grasshoppers and weevils.
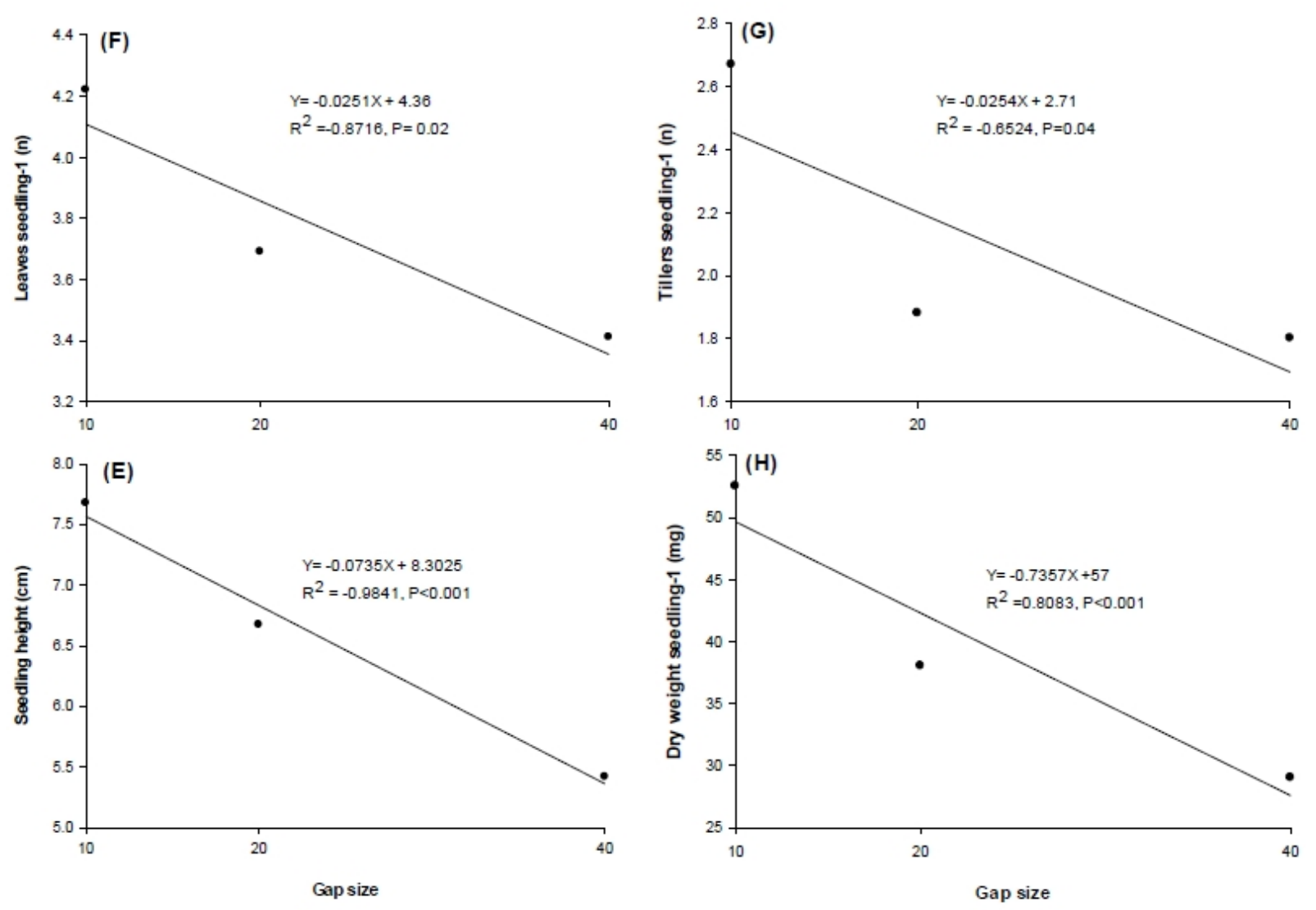

Fig.4.Relationships of gap size and seedling height, number of leaves per seedling, number of tillers per seedling and dry weight per seedling of Agropyron cristatum (E, F, G, H).

\section{Conclusions}

Generally, creating suitable micro-site by gap disturbance can give a better opportunity for the regeneration of native species. Gap disturbance increased the soil moisture and soil temperature compared to controls, and increased the germination rate of sowing seeds. However, different species differ in their response to gap disturbance.The bigger size gap was more favorable to the seedling establishment of Stipa krylovii.Agropyron cristatum only showed relatively good performance in small size gap, and the seedling establishment of Stipa kryloviiwas betterthan that of Agropyron cristatum. Predationsof insects played a certain role in regulating the community structure. It is due to the insects' food preference as well as the difference in tolerance between the two species.Stipa krylovii seedling establishment is facilitated by the availability ofnatural gaps. That's why Stipa krylovii is a sub-dominant species and Agropyron cristatum is a companion species in this semi-arid grassland.

\section{Acknowledgements}

Research was funded byBeijng Finance Bureau Science and Technology Innovation Project of"Beijng Monitoring Station of Degraded Ecosystem Restoring in the Long Term Construction (KJCX20140301)" and "Research and Demonstration of Technologies on Efficient Grassland Construction for the Restoration of Sandy Wasteland (KJCX20151201)", also postdoctoral fund "Effects of Soil Moisture Dynamics on Smooth Brome's Bud Bank". We thank all students and 
field assistants who helped us with the field work. We thank the Grassland Vegetation Restoration and Reconstruction Key Laboratory for their support.

\section{References}

1. Tilman, D. and S. Pacala, The maintenance of species richness in plant communities. Species diversity in ecological communities, 1993: p. 13-25.

2. Aguilera, M.O. and W.K. Lauenroth, Seedling Establishment in Adult Neighborhoods Intraspecific Constraints in the Regeneration of the Bunchgrass Bouteloua-Gracilis. Journal of Ecology, 1993. 81(2): p. 253-261.

3. Liu, G., et al., Effects of adult neighbour and gap size on seedling emergence and early growth of Bromus inermis Leyss. Ecological Research, 2008. 23(1): p. 197-205.

4. Wagner, M., et al., The germination niches of grassland species targeted for restoration: effects of seed pre-treatments. Seed Science Research, 2011: p. 1-15.

5. Bullock, J.M., et al., Gap Colonization as a Source of Grassland Community Change-Effects of Gap Size and grazing on the Rate and Mode of Colonization By Different Species. Oikos, 1995. 72(2): p. 273-282.

6. Bullock, J.M., Gaps and seedling colonization. Seeds: the ecology of regeneration in plant communities, ed. M. Fenner. 2000: CABI Publishing. 375-395.

7. Pakeman, R.J. and J.L. Small, The role of the seed bank, seed rain and the timing of disturbance in gap regeneration. Journal of Vegetation Science, 2005. 16(1): p. 121-130.

8. Clark, C., et al., Are plant populations seed limited? a critique and meta - analysis of seed addition experiments. The American Naturalist, 2007. 170(1): p. 128-142.

9. Wang, J.H., et al., Competition between Stipa grandis and Cleistogenes squarrosa. Journal of Arid Environments, 2008. 72(2): p. 63-72.

10. Jian, S.U.N., et al., Survival strategy of Stipa krylovii and Agropyron cristatum in typical steppe of Inner Mongolia. Acta Ecologica Sinica, 2011. 31(8).

11. Meng, 1. and H. Gao. Current Situation of Chinese Degraded Grassland and Regeneration Regimes. in China International Grass Industry Development Comference. 2002. China,BeiJing.

12. Liu, G.X. and J.G. Han, Influence of grassland gap on seedling establishment of Leymus chinensis (Trin.) Tzvel. Rangeland Ecology \& Management, 2007. 60(6): p. 624-631.

13. King, T.J., The roles of seed mass and persistent seed banks in gap colonisation in grassland. Plant Ecology, 2007. 193(2): p. 233-239.

14. Cahill, J.F., Interactions between root and shoot competition vary among species. Oikos, 2002. 99(1): p. 101-112.

15. Armas, C. and F.I. Pugnaire, Belowground zone of influence in a tussock grass species. Acta Oecologica, 2011. 37(3): p. 284-289.

16. McConnaughay, K.D.M. and F.A. Bazzaz, Interactions among colonizing annuals: is there an effect of gap size? Ecology, 1990. 71(5): p. 1941-1951.

17. Hanley, M.E., M. Fenner, and P.J. Edwards, The effect of mollusc: Grazing on seedling recruitment in artificially created grassland gaps. Oecologia, 1996. 106(2): p. 240-246.

18. Louda, S.M. and J.E. Rodman, Insect herbivory as a major factor in the shade distribution of a native crucifer (Cardamine cordifolia A. Gray, bittercress). Journal of Ecology, 1996. 84(2): p. 229-237.

19. Hanley, M.E., Seedling herbivory and the influence of plant species richness in seedling neighbourhoods. Plant Ecology, 2004. 170(1): p. 35-41. 